\title{
Factors associated with the use of potentially inappropriate medications by elderly people with hypertension
}

\author{
Fatores associados ao uso de medicamentos potencialmente inapropriados por idosos com hipertensão \\ Factores asociados al uso de medicamentos potencialmente inapropiados por ancianos con hipertensión
}

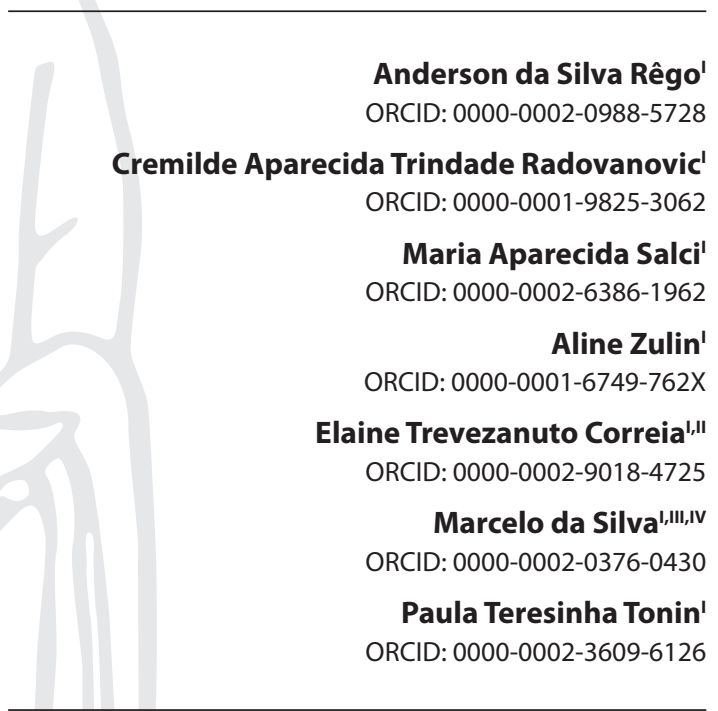

'Universidade Estadual de Maringá. Maringá, Paraná, Brazil. "Secretaria Municipal de Saúde. Paranavaí, Paraná, Brazil. I'ISecretaria Municipal de Saúde. Maringá, Paraná, Brazil.

"Universidade Cesumar. Maringá, Paraná, Brazil.

How to cite this article:

Rêgo AS, Radovanovic CAT, Salci MA, Zulin A, Correia ET,

Silva $M$, et al. Factors associated with the use of potentially inappropriate medications by elderly people with hypertension. Rev Bras Enferm. 2020;73(Suppl 3):e20200078. doi: http://dx.doi.org/10.1590/0034-7167-2020-0078

Corresponding author:

Anderson da Silva Rêgo

E-mail: andersondsre@gmail.com

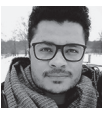

EDITOR IN CHIEF: Antonio José de Almeida Filho ASSOCIATE EDITOR: Álvaro Sousa

Submission: 05-12-2020 Approval: 09-20-2020

\section{ABSTRACT}

Objective: to analyze factors associated with the use of potentially inappropriate medications by elderly people with hypertension. Method: a cross-sectional study, conducted in the first semester of 2016, with elderly people undergoing treatment for hypertension, living in the city of Maringá. Interviews, medical records analysis, and measurement of clinical and anthropometric parameters of the participants were carried out. Inferential analysis was used. Results: a total of 260 elderly people who used potentially inappropriate medications participated in the study. The high use of these medications was associated with clinical and anthropometric conditions, such as obesity $(p=0.022)$, smoking $(p=0.004)$, polypharmacy $(p=0.034)$ and the health services provided, such as organizationally accessible treatment $(p=0.027)$ and consultation time $(p=0.007)$, predisposing to low adherence to routine consultations $(p=0.003)$. Conclusion: it was shown that the factors associated with the use of potentially inappropriate medications were associated with anthropometric, clinical, and organizational variables, intrinsic to the family health strategy.

Descriptors: Hypertension; Anthropometry; Aged; Family Health Strategy; Potentially Inappropriate Medication List.

\section{RESUMO}

Objetivo: analisar os fatores associados ao uso de medicamentos potencialmente inapropriados por idosos com hipertensão. Método: estudo transversal, realizado no primeiro semestre de 2016, com idosos em tratamento da hipertensão, residentes no município de Maringá. Realizou-se entrevista, análise de prontuário e aferição de parâmetros clínicos e antropométricos dos participantes. Utilizou-se análise inferencial para tratamento das variáveis. Resultados: participaram do estudo 260 idosos, que faziam uso de medicamentos potencialmente inapropriados. $\mathrm{O}$ uso elevado dessas medicações se associou às condições clínicas e antropométricas, como obesidade $(\mathrm{p}=0,022)$, tabagismo $(\mathrm{p}=0,004)$, polifarmácia $(\mathrm{p}=0,034) \mathrm{e}$ aos serviços de saúde ofertados, como tratamento organizacionalmente acessível $(p=0,027)$ e tempo de consulta $(p=0,007)$, predisponente à baixa aderência às consultas de rotina $(p=0,003)$. Conclusão: evidenciou-se que os fatores associados ao uso de medicamentos potencialmente inapropriados se associaram a variáveis antropométricas, clínicas e organizacionais, intrínsecas a estratégia saúde da família.

Descritores: Hipertensão; Antropometria; Idosos; Estratégia Saúde da Família; Lista de Medicamentos Potencialmente Inapropriados.

\section{RESUMEN}

Objetivo: analizar factores asociados con el uso de medicamentos potencialmente inapropiados por ancianos con hipertensión. Método: estudio transversal, realizado en el primer semestre de 2016, con ancianos en tratamiento por hipertensión, residentes en la ciudad de Maringá. Se realizaron entrevistas, análisis de historias clínicas y medición de parámetros clínicos y antropométricos de los participantes. Se utilizó análisis inferencial para tratar las variables. Resultados: en el estudio participaron 260 ancianos, que utilizaron medicamentos potencialmente inapropiados. El alto uso de estos medicamentos se asoció con condiciones clínicas y antropométricas, como obesidad $(p=0,022)$, tabaquismo $(p=0,004)$, polifarmacia $(p=0,034)$ y los servicios de salud ofrecidos, como tratamiento organizacionalmente accesible $(p=0,027)$ y tiempo de consulta $(p=0,007)$, lo que predispone a una baja adherencia a las consultas de rutina $(p=0,003)$. Conclusión: se evidenció que los factores asociados al uso de medicamentos potencialmente inapropiados se asociaron con variables antropométricas, clínicas y organizacionales, intrínsecas a la Estrategia de Salud Familiar.

Descriptores: Hypertension; Antropometría; Anciano; Estrategia Salud de la Familia; Lista de Medicamentos Potencialmente Inapropiados. 


\section{INTRODUCTION}

The demographic and epidemiological transition has increased the life expectancy of the world population, with a significant increase in chronic and acute morbidities, concerned to most elderly people ${ }^{(1-2)}$. Regarding Chronic Non-Communicable Diseases, hypertension has a high incidence in Brazil. In the year 2019 data from the Surveillance of Risk and Protection Factors for Chronic Diseases by Telephone Survey, indicate that $24.5 \%$ of the Brazilian population self-reported hypertension, most being elderly (59.3\%), with low educational level (41.5\%) and who use antihypertensive medication $(83.1 \%)^{(3)}$.

About the structure for the elderly care with $\mathrm{AH}$, data from the World Health Organization (WHO) indicate that, despite the progress, accessibility to health services remains limited in several parts of the world, mainly in developing countries, such as Brazil. The actions offered to the elderly population with hypertension to reduce complications related to chronic morbidity are still incipient, mainly because they understand that the work of the Family Health Strategy (FHS) teams is a time-consuming and gradual capillarity process for all health regions and its expansion to suburbs ${ }^{(1-2,4)}$.

Given the complexity of the elderly care with hypertension, medication therapy needs to be constantly monitored by health professionals at the primary level ${ }^{(2)}$. Some medications are inappropriate for the population over 60 years old due to the adverse effects inherent to their mechanism of action, which offer more risks than benefits, with triggering of symptoms related to bradycardia, toxicity, when in prolonged use, or risk of falls ${ }^{(5)}$.

Thus, the American Geriatrics Society has compiled criteria for the Potentially Inappropriate Medication (PIM) for elderly people called Beers Criteria ${ }^{\circ}$. These criteria subsidize several health professionals to prescribe safe medications to the elderly in the treatment of morbidities, following caution when the interactions cause deleterious effects to the elderly population. Beers Criteria has been updated recently to make them more specific to clinical practice and to be relevant in private care settings(6).

In the context of Primary Health Care (PHC), the use of more than one medication among the elderly is high, which classifies them as polypharmacy. Polypharmacy and the accentuated use of PIM can cause the iatrogenic cascade, in which there is a need for health professionals to know the selection, prescription and dispensing of medications, especially in elderly people with hypertension, to avoid complications inherent to chronic morbidity, enhanced by the use of these medications ${ }^{(5,7-8)}$.

Therefore, it is questioned: what are the sociodemographic, anthropometric, clinical and organizational factors, inherent to the FHS teams, influence the prevalence of the use of PIM by elderly people with hypertension registered and monitored by the Clinical Management System for Hypertension and Diabetes Mellitus of Primary Care (SISHIPERDIA) in the Primary Health Care network in the city of Maringá, Paraná, Brazil?

\section{OBJECTIVE}

To analyze the factors associated with the use of potentially inappropriate medication by elderly people with hypertension.

\section{METHOD}

\section{Ethical aspects}

This research followed the guidelines of Resolution 466/2012, being submitted to the city's health department. After approval, it was forwarded to the Ethics and Research Committee with Human Beings, receiving a positive opinion to be carried out. All participants signed the Informed Consent Form (ICF) in two copies.

\section{Design, location, and period}

This is a quantitative, cross-sectional study that followed the recommendations of the Strengthening the Reporting of Observational Studies in Epidemiology (STROBE) ${ }^{(9)}$, held in the city of Maringá, Paraná, Brazil, with an estimated population of 403,063 people. The city health care network is distributed in a decentralized manner, and in the period of data collection, it had a total of 34 Basic Health Units (BHU) and 74 FHS teams, with a $68.01 \%$ population coverage ${ }^{(10)}$. Data collection was carried out in the first semester of 2016, in the BHU, in a private location, provided by the responsible professionals.

\section{Sample: inclusion and exclusion criteria}

Participants were people with hypertension enrolled in the program SISHIPERDIA, which is a program for enrolment and monitoring people with Hypertension and Diabetes Mellitus ${ }^{(11)}$. The number of people with hypertension registered in the program was retrieved from the Municipal Health Department. At the time of the study, a total of 29,035 people was actively enrolled in 74 teams, distributed in $34 \mathrm{BHU}$.

As an inclusion criterion, it was adopted to have updated medical records, with a medical prescription, attendance to at least one routine consultation, scheduled by the BHU teams, being the year of 2015 a parameter for measuring and recording the participant's clinical evolution in the hypertension treatment. The rural population was excluded, as it belongs to a region far from the city, in which the FHS teams, even belonging to a $\mathrm{BHU}$ in the urban area of the city, providing care in a space provided by a local religious institution, being considered as bias, since the PHC attributes aim at geographic accessibility.

Given the inclusion and exclusion criteria, and with the list made available by the Municipal Health Department, a representative sample was gathered, calculated by using a stratified random sampling process, according to the number of people followed by each $\mathrm{BHU}$, considering an estimated error of $5 \%$ and $95 \%$ confidence interval, and an additional $15 \%$ for possible losses. Considering losses due to death, verbalization difficulties and refusals, as well as the theme of PIM, specific to the population $\geq 60$ years old, the final sample of this study was composed of 260 elderly people.

\section{Study protocol}

Initially, the objectives of the study were presented to the managers of the BHU, and the dates for scheduling the SISHIPERDIA 
meetings were requested. With these data, a strategic schedule was made so that all teams included in the study could be attended promptly. Three nurses participated in the data collection, master's degree, and doctoral students in nursing. Everyone who performed the data collection received previous training for the instruments of data collection, analysis of medical records, development of greater management for interview conduction and verification of anthropometric and clinical data.

Two instruments were used. The first evaluated the satisfaction of elderly people with hypertension towards the PHC services, having a sociodemographic, anthropometric, clinical profile and questions related to $\mathrm{PHC}$ attributes, divided into accessibility to diagnosis and treatment, attendance/adherence, list of services, care coordination, family focus and community guidance ${ }^{(12)}$. In this study, the questions related to attendance/bonding with health professionals, accessibility to treatment and the list of services were categorized based on the composed index of the questions related to the aforementioned blocks, resulting from the analysis of non-hierarchical grouping by distribution.

The instrument' questions have five possible answers, as in a Likert scale, being: "never", "rarely", "sometimes", "almost always" and "always", also the options "not applicable" and "doesn't know/ didn't answer" to make all available responses possible. Subsequently, the results were classified as adequate $(\geq 4)$, inadequate $(<3)$ and regular $(\geq 3 \text { and }<4)^{(13)}$. The second instrument refers to the economic profile assessment, classifying the purchasing power of the household head, entitled Brazil Economic Classification Criterion (BECC) ${ }^{(14)}$. The results of this evaluation were grouped into $A B$ (good conditions), $C$ (regular conditions) and DE (low conditions).

Therefore, an analysis of medical records was carried out to collect data on attendance to scheduled clinical consultations, and it was considered adequate the participation in at least three consultations per year, according to the recommendations of the Ministry of Health $(\mathrm{MH})^{(11)}$; medication profile; polypharmacy classification, which was defined based on the evaluation of medications used daily by the elderly. According to the Elderly Guidebook, it was considered the sum of the different prescribed medications and their daily dosage, and the elderly in polypharmacy, when daily medications intake exceeded five ${ }^{(15)}$.

Furthermore, the clinical variables were collected from the medical records analyzed, in which it was observed the record of the evolution of the nursing and medical team, as well as the current clinical diagnosis, the presence of other chronic morbidities and lifestyle habits, such as alcohol and cigarette consumption, from the evolutions made by the teams of the Family Health Support Center (FHSC), which provided support to the FHS teams.

Beers criteria, developed by specialists from the American Geriatrics Society ${ }^{(6)}$ were used, to identify PIM prescribed by health professionals working in the FHS teams in the city. Participants were categorized as PIM users, if there were medication described in the criteria. Chart 1 shows the medication prescribed to the elderly participants in the study, according to the first level, which corresponds to the main anatomical group and the second level, which refers to the therapeutic subgroup of Anatomical Therapeutic Chemical (ATC) ${ }^{(16)}$, belonging to the Beer criteria( ${ }^{(6)}$.
Chart 1 - List of potentially inappropriate medications prescribed to elderly people with hypertension monitored by the Family Health Strategy, Maringá, Paraná, Brazil, 2016

\begin{tabular}{|c|c|c|}
\hline ATC Group* & ATC subgroup & Medicament \\
\hline $\begin{array}{l}\text { Cardiovascular } \\
\text { system }\end{array}$ & $\begin{array}{l}\text { Antihypertensive } \\
\text { agents, calcium } \\
\text { channel blockers, } \\
\text { diuretics, loop } \\
\text { diuretics }\end{array}$ & $\begin{array}{l}\text { Clonidine, methyldopa, } \\
\text { digoxin, nifedipine, } \\
\text { amiodarone, } \\
\text { spironolactone, } \\
\text { doxazosin mesylate, } \\
\text { furosemide }\end{array}$ \\
\hline Nervous system & $\begin{array}{l}\text { Tertiary tricyclic } \\
\text { antidepressants, } \\
\text { selective serotonin } \\
\text { reuptake inhibitors, } \\
\text { barbiturates, } \\
\text { psychoanaleptics, } \\
\text { anticonvulsants, } \\
\text { antipsychotics, } \\
\text { neuroleptics }\end{array}$ & $\begin{array}{l}\text { Amitriptyline, } \\
\text { imipramine, paroxetine } \\
\text { hydrochloride, } \\
\text { nortriptyline, } \\
\text { clomipramine } \\
\text { hydrochloride, fluoxetine, } \\
\text { phenobarbital, } \\
\text { alprazolam, clonazepam, } \\
\text { carbamazepine, } \\
\text { mirtazapine, gabapentin, } \\
\text { haloperidol, and } \\
\text { risperidone }\end{array}$ \\
\hline $\begin{array}{l}\text { Gastrointestinal } \\
\text { system }\end{array}$ & $\begin{array}{l}\text { Gastrointestinal } \\
\text { antispasmodics, } \\
\text { antacids, medicines to } \\
\text { treat peptic ulcer and } \\
\text { flatulence }\end{array}$ & $\begin{array}{l}\text { Megestrol, mineral } \\
\text { oil, scopolamine, } \\
\text { omeprazole, } \\
\text { metoclopramide, } \\
\text { ranitidine }\end{array}$ \\
\hline $\begin{array}{l}\text { Endocrine } \\
\text { system }\end{array}$ & Hypoglycemic & Glimepiride \\
\hline $\begin{array}{l}\text { Musculoskeletal } \\
\text { system }\end{array}$ & $\begin{array}{l}\text { Anti-inflammatory } \\
\text { and anti-rheumatic, } \\
\text { systemic non-steroidal } \\
\text { anti-inflammatory }\end{array}$ & $\begin{array}{l}\text { Diclofenac sodium and } \\
\text { ibuprofen }\end{array}$ \\
\hline $\begin{array}{l}\text { General anti- } \\
\text { infectives for } \\
\text { systemic use }\end{array}$ & $\begin{array}{l}\text { Antibiotics for } \\
\text { systemic use and } \\
\text { quinolone antibiotics }\end{array}$ & $\begin{array}{l}\text { Sulfametazoltrimetoprime, } \\
\text { ciprofloxacin }\end{array}$ \\
\hline $\begin{array}{l}\text { Blood and } \\
\text { hematopoietic } \\
\text { organs }\end{array}$ & $\begin{array}{l}\text { Antithrombotic and } \\
\text { antiplatelet drugs }\end{array}$ & $\begin{array}{l}\text { Warfarin, acetylsalicylic } \\
\text { acid }\end{array}$ \\
\hline
\end{tabular}

For the collection of anthropometric and clinical data, the Brazilian Guidelines on Obesity were followed ${ }^{(17)}$, anchored in the guidelines proposed by the Elderly Guidebook, developed by $\mathrm{MH}^{(15)}$. Digital anthropometric scales were used to measure weight and an anthropometric measuring tape was used to measure height and waist circumference (WC). For the collection of pressure values at the time of the interviews, aneroid sphygmomanometers were used, with current regulation and calibration according to the Brazilian Society of Cardiology ${ }^{(18)}$.

The technical procedure for blood pressure measuring was performed with the participant in a seated position. It was not possible to check pressure parameters with the participant in other positions due to the physical structure and organizational dynamics of the BHU. Values for systolic blood pressure $\leq 140$ $\mathrm{mmHg}$ and diastolic blood pressure $\leq 90 \mathrm{mmHg}^{(18)}$ were established as adequate blood pressure control.

Obesity was classified according to Brazilian Obesity Guidelines (17) also according to Elderly Guidebook ${ }^{(15)}$, being considered overweight elderly people with Body Mass Index (BMI) $\left(\mathrm{kg} / \mathrm{m}^{2}\right)$ above 27. To check abdominal obesity, the waist/height ratio (WHR) and WC values were coded from the cutoff point assigned by the Corrêa study ${ }^{(19)}$ and Brazilian Obesity Guidelines ${ }^{(17)}$, respectively. The 
Conicity Index (Col) was verified using the equation proposed by Pitanga and Lessa, as well as the cutoff points for determining the adequacy of the referred parameter ${ }^{(20)}$.

\section{Analysis of results and statistics}

The data were double inputted in a Microsoft Excel 2016 spreadsheet and sent for analysis with the aid of the Statistical Package for Social Sciences (SPSS) software, version 20.0. The KolmogorovSmirnov test was used to identify the normality of the data, with Lilliefors correction. For the analysis of the factors associated with the use of PIM, it was defined as a dependent variable the "dependent use of PIM", grouped based on the analysis of the medication profile, prescribed by health professionals. The independent variables were the sociodemographic, clinical, and anthropometric profiles and grouping questions related to FHS organizational issues.

Logistic regression analysis was used at two different times. In the first stage, each dependent variable was analyzed in isolation to verify a direct relationship with the use of PIM, and those that resulted in a potential of significance $>0.20$ were classified for the multivariate stage. The variables classified in the previous step were analyzed from the interactions by the Stepwise process, forming the multivariate model with the explanatory observations. Statistical significance was set at $p<0.05$, and associations were estimated using Odds Ratio (OR), with a 95\% confidence interval as a measure of accuracy. The multivariate model showed good adjustment quality, estimated by the Hosmer-Lemeshow test.

\section{RESULTS}

A total of 260 elderly people undergoing treatment for hypertension participated in the study, the majority from 60 to 69 years old $(48.8 \%)$, female $(67.3 \%)$, white $(64.6 \%)$, with less than eight years of education ( $84.2 \%)$, living with a partner $(53.4 \%)$, retired $(74.2 \%)$ and classified in extract $C(60.4 \%)$ in which is the purchasing power of the household head. More than half of the interviewees (54.2\%) were classified as PIM users (Table 1).

Table 2 shows that, among anthropometric variables, the elderly with obesity $(\mathrm{OR}=1.98 ; 95 \% \mathrm{Cl} 1.10-3.58)$ and altered waist circumference $(\mathrm{OR}=2.90 ; 95 \% \mathrm{Cl} 1.27-5.49)$ are more likely to use PIM. As for clinical factors, it was evidenced that elderly people who are smokers $(\mathrm{OR}=4.07 ; 95 \% \mathrm{Cl} 1.57-10.50)$ and classified as polypharmacy $(\mathrm{OR}=1.51 ; 95 \% \mathrm{Cl}=1.08-2.70)$ are more likely to have the same result. The anthropometric and clinical factors were adjusted for the sociodemographic variables sex and marital status, shown in Table 1.

It is observed that the elderly who evaluated how to control the offered consultation time $(\mathrm{OR}=2.41 ; 95 \% \mathrm{Cl} 1.26-4.61)$ and accessibility to treatment $(\mathrm{OR}=1.44 ; 95 \% \mathrm{Cl} 1.22-2.84)$, are more likely to use PIM. Elderly people who are not attending to routine consultations ( $\mathrm{OR}=0.40 ; 95 \% \mathrm{Cl} 0.22-0.74)$ are less susceptible to using these medications due to the absence from SISHIPERDIA meetings and receiving medication prescriptions (Table 3 ). The variables with statistical significance were adjusted for the sociodemographic variables sex and marital status, shown in Table 1.

Table 1 - Sociodemographic factors associated with the use of potentially inappropriate medications by elderly people with hypertension, monitored by the Family Health Strategy, Maringá, Paraná, Brazil, 2016

\begin{tabular}{|c|c|c|c|c|c|c|}
\hline \multirow{3}{*}{ Age } & \multicolumn{2}{|c|}{ Use of PIM } & \multicolumn{2}{|c|}{ Gross univariate } & \multicolumn{2}{|c|}{$\begin{array}{l}\text { Adjusted multivariate } \\
\text { analysis }\end{array}$} \\
\hline & \multirow[t]{2}{*}{$\begin{array}{c}\text { No }(n=119) \\
n(\%)\end{array}$} & $\begin{array}{c}\text { Yes }(n=141) \\
n(\%)\end{array}$ & \multicolumn{2}{|c|}{$\begin{array}{c}\text { analysis } \\
\text { OR }(95 \% \mathrm{Cl})\end{array}$} & \multicolumn{2}{|c|}{$\begin{array}{c}\text { analysis } \\
\text { OR }(95 \% \mathrm{Cl})\end{array}$} \\
\hline & & & & & & \\
\hline $60-69$ years old & $66(25.4)$ & $61(23.4)$ & 1 & & & \\
\hline $70-79$ years old & $36(13.8)$ & $60(23.1)$ & $1.60(0.93-2.73)$ & $0.085^{*}$ & & \\
\hline 80 - 89 years old & $15(5.8)$ & $20(7.7)$ & $1.27(0.54-2.99)$ & 0.581 & & \\
\hline$>90$ years old & $2(0.8)$ & & & & & \\
\hline \multicolumn{7}{|l|}{ Sex } \\
\hline Male & $33(12.7)$ & $52(20.0)$ & 1 & & 1 & \\
\hline Female & $86(33.1)$ & $89(34.2)$ & $0.65(0.38-1.11)$ & $0.118^{*}$ & $0.67(0.35-1.30)$ & 0.245 \\
\hline \multicolumn{7}{|l|}{ Race/color } \\
\hline White & $80(30.8)$ & $88(33.8)$ & 1 & & & \\
\hline Black & $14(5.4)$ & $24(9.2)$ & $1.55(0.75-3.21)$ & 0.231 & & \\
\hline Mixed-race & $25(9.6)$ & $29(11.2)$ & $1.05(0.57-1.95)$ & 0.866 & & \\
\hline \multicolumn{7}{|l|}{ Schooling } \\
\hline 0 to 8 years & $97(37.3)$ & $122(46.9)$ & 1 & & & \\
\hline$>8$ years & $22(8.5)$ & $19(7.3)$ & $0.68(0.35-1.34)$ & & & \\
\hline \multicolumn{7}{|l|}{ Marital status } \\
\hline With a partner & $57(21.9)$ & $87(31.5)$ & 1 & & 1 & \\
\hline Without a partner & $62(23.8)$ & $54(20.8)$ & $1.75(10.6-2.87)$ & $0.026^{*}$ & $1.17(0.59-2.29)$ & 0.648 \\
\hline \multicolumn{7}{|l|}{ Occupation } \\
\hline Employed & $13(5.0)$ & $10(3.8)$ & 1 & & & \\
\hline Unemployed & $24(9.2)$ & $20(7.7)$ & $1.08(0.39-2.99)$ & 0.877 & & \\
\hline Retired & $82(31.5)$ & $111(42.7)$ & $1.76(0.73-4.21)$ & 0.204 & & \\
\hline \multicolumn{7}{|l|}{ BECC } \\
\hline$A B$ & $44(17.0)$ & $51(19.6)$ & 1 & & & \\
\hline$C$ & 51 (19.6) & $55(21.1)$ & $0.93(0.53-0.65)$ & 0.799 & & \\
\hline $\mathrm{DE}$ & $24(9.2)$ & 35 (13.5) & $1.25(0.65-2.42)$ & 0.494 & & \\
\hline
\end{tabular}

Note: PIM - potentially inappropriate medications; OD - Odds Ratio; Cl-Confidence Index. BECC - Brazil Economic Classification Criterion; AB - good conditions; C-regular conditions; DE- low conditions. * Variables with $p<0.20$ and were included in the multivariate model. 
Table 2 - Anthropometric and clinical factors associated with the use of potentially inappropriate medications by elderly people with hypertension monitored by the Family Health Strategy, Maringá, Paraná, Brazil, 2016

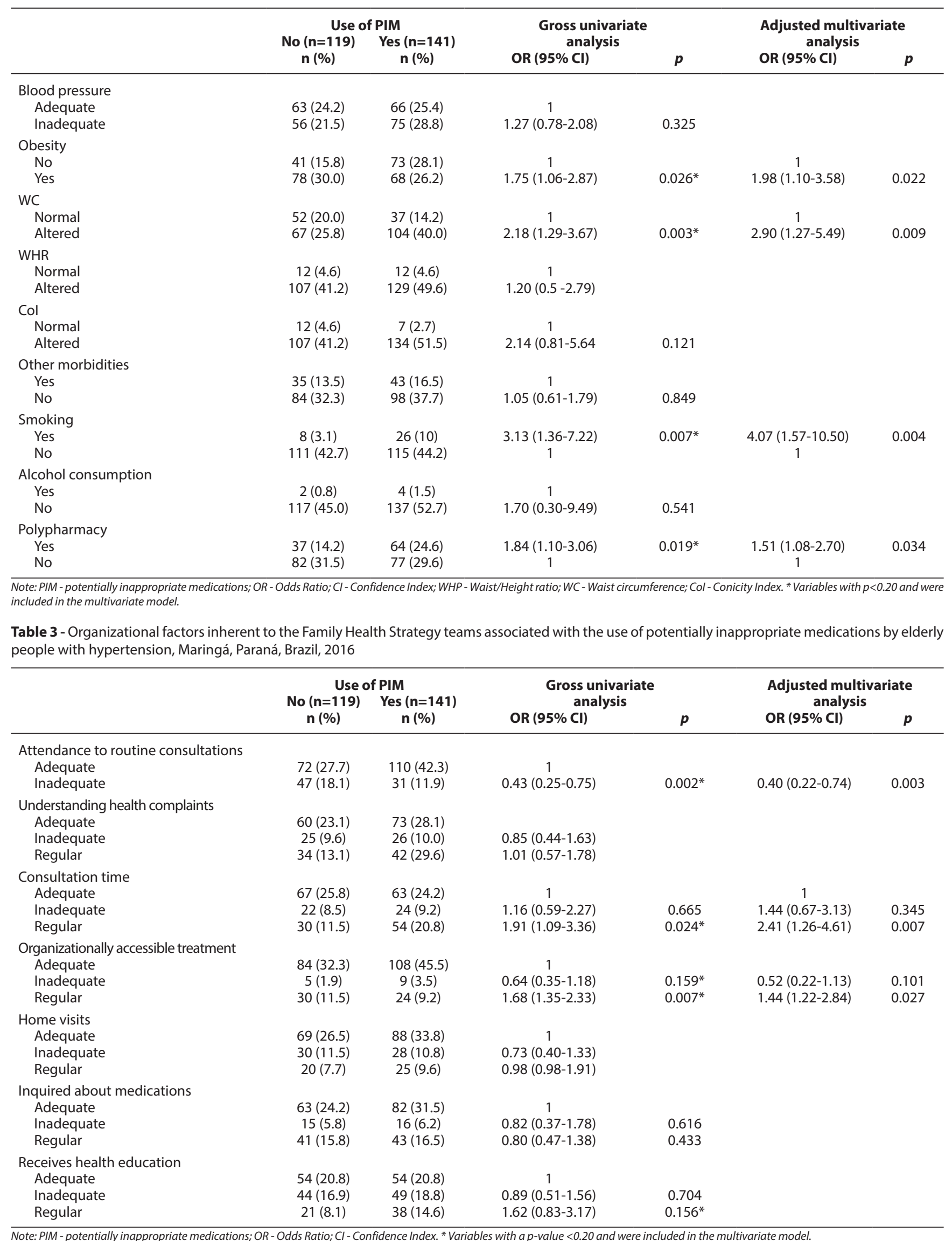

Note: PIM - potentially inappropriate medications; OR - Odds Ratio; $\mathrm{Cl}$ - Confidence Index. ${ }^{*}$ Variables with a p-value $<0.20$ and were included in the multivariate model. 


\section{DISCUSSION}

In this research, we present the distinct sociodemographic, anthropometric, clinical, and organizational variables associated with the use of PIM by elderly people with hypertension. According to the adopted multivariate model, we show that elderly people with obesity and altered waist circumference are more active consumers of PIM. Also, we highlighted that the significant clinical explanatory variables for the use of these medications were obesity, altered waist circumference, polypharmacy, and the use of cigarettes. As for organizational factors, we highlighted that routine attendance to consultations proved to be an opposite factor to the use of PIM due to the absence from SISHIPERDIA meetings and receiving medication prescriptions. Dissatisfaction with accessibility to treatment and consultation time offered by FHS teams enhances the use of PIM by elderly people with hypertension.

When it comes to obesity and altered waist circumference, which we highlight as factors that contribute to the use of PIM, these are inherent to dietary habits and physical activity practices. We emphasize that the elderly's physiological conditions and changes, such as decreased bone mineral density and increased visceral fat, may contribute to the occurrence of other morbidities, potentiating the use of multiple medications, which may cause the prescription of $\mathrm{PIM}^{(16,21-24)}$.

The PHC as the main mediator in the elderly's health, especially when they have chronic morbidities, such as hypertension, has elements that can increase the attendance of the elderly in the practice of physical activity and dietary reeducation, supported by health education, mainly in units that have other health professionals, such as nutritionists, psychologists and physical educators as matrix support. It is important to offer parameters that support the reflection and change in lifestyle and diet habits of this population with hypertension through interprofessional interventions, mainly health education ${ }^{(25-26)}$.

Moreover, when carrying out health education practices, we also provide subsidies for elderly people who make use of cigarettes, considering that smoking was a statistically significant factor when associated with the consumption of PIM. Scientific evidence on cigarette use is associated with inadequate lifestyle habits and the chances of having a compromised nutritional profile. The role of the health professional, especially the prescribers of medication in PHC, is the responsibility of the individualized care settings, in which we can reduce the possibility of the iatrogenic cascade occurring in the elderly, caused by polypharmacy ${ }^{(22,26)}$.

The care practices, with strategic interventions for smoking cutoff, occur based on our training and graduation/knowledge about the intervention methodologies, which allows the approach to the patient, adding the risk factor in question in the routine of our clinical practice of anamnesis. We emphasize our importance, as health professionals, in approaching the elderly who smokes, when we use strategies to reduce smoking, and encourage smoking cutoff, according to the services' protocols provided by the FHS ${ }^{(27)}$.

Concerning polypharmacy, it is inherent to the aging process and is connected to the health needs of this population, which often has more than one morbidity, including diseases related to the central nervous system and inappropriate lifestyle habits, such as physical inactivity and inadequate diet. The sum of these factors provides multiple medication prescriptions, which may be related to PIM, mainly in $\mathrm{PHC}^{(7,22-23,26,28-29)}$.

Despite the wide propagation of Beers criteria and the PIM list, we still prescribe these medications due to the limited knowledge and the limited applicability of these checklists, linked to the lack of opportune time to organize our care strategy and the absence of alternative medications for PIM substitution. Thus, elderly people with $\mathrm{AH}$, who receive medication through the public health system for the hypertension treatment, can be considered a factor so that we can perform PIM replacements, considering their clinical, demographic, socioeconomic and educational status ${ }^{(30)}$.

The resistance of the elderly and the financial limitations regarding the change from inappropriate medications to another alternative therapy affects the continuity of medications. When we replace these medications, without considering the intrinsic conditions of the elderly, we can be held responsible for nonattendance to routine consultations, planned by health professionals, as well as for the deficiency of the clinical diagnosis and in the proper prescription of medications, when necessary ${ }^{(30)}$.

In line with this matter, the finding is consistent with the literature, in which non-attendance to routine consultations does not imply casual use of PIM, supported by the absence of medical prescriptions that may compromise the therapy of choice for the treatment of hypertension, causing complications from its chronicity. Nevertheless, the absence of the elderly in routine consultations, related to non-attendance to medication therapy, leads to a higher probability of hospitalization for preventable causes, which leads to greater public spending on restoring health, as well as a significant impact on the quality of life of these people ${ }^{(2)}$.

As for the consultation time during the SISHIPERDIA consultations, we reveal that the elderly using PIM evaluated this service as regular. In this scenario, we understand that the absence of a link between health professionals and the elderly can compromise attendance to treatment, as well as generate doubts related to medication therapy for morbidity, increasing our unawareness, as health professionals, about other parameters that influence blood pressure control and adequate attendance to routine consultations $s^{(2,31)}$.

The participants in this study had a quarterly care schedule according to the patient's complexity. Most of the group meetings in this program were held by micro areas of the FHS teams, with a large number of patients to be attended in a single period, which implies the practice of replicating prescriptions with a brief approach to the patient, concentrating on the disease and not the user, which focused on dissatisfaction with the consultation time, evaluated by the interviewees in this study.

We reiterate the possibility of using therapeutic listening as a model for integrating the user into services, which promotes adherence to medication therapy, reinforcing the self-care practices of these people, which can impact on anthropometric parameters, adequate blood pressure control and significant consultation time in elderly care ${ }^{(32)}$. It is necessary that the follow-up carried out for the elderly with hypertension has elements that can break up with the biomedical model centered on the disease. Mechanized consultation can discourage autonomy and self-care, leading to the need for secondary level care due to acute events resulting from chronic morbidities, such as hypertension ${ }^{(2,32)}$. 
In this scenario, we stress the demand for interventions, based on our care practices, with interventions related to the consultation time, explanatory factor for dissatisfaction with the organizational accessibility to treatment. We understand that organizational accessibility to treatment is based on the performance of health professionals about services offered to the population. The principle of integrality needs to be performed, mainly in PHC, as a gateway to health services, and the organization of the work process of the FHS teams is the main tool for matching the supply and demand of the population's health needs ${ }^{(13)}$.

The difficulties of health professionals in monitoring the elderly with hypertension, such as care focused on the disease, academic training based on the biomedical model, lack of intersectionality and care discontinuity in the care network are evident in evaluative studies of primary care ${ }^{(4,13,31,33)}$. Thus, we warn about the organization of teams working in the FHS, predictive of the offer improvement and demand monitoring of elderly people in the treatment of hypertension, by training on the process and management of health actions for this part of the population, which makes use of PIM for their age group ${ }^{(2,4-5)}$.

\section{Limitations of the study}

This research has limitations, as it is performed only with the elderly population with hypertension, who uses PIM in PHC, not being interviewed health professionals, who could provide more evidence about the factors associated with the use of PIM in the elderly population. The fact that medication records and medication prescriptions are analyzed, in which we highlight the use of PIM by $54.2 \%$ of the elderly with hypertension, does not cover the side effects that underlie the Beers criteria, a reference used in the classification of inappropriate medications. Thus, we reinforce the need for studies that can quantify the damage caused by PIMs in this population, according to their diagnosis and clinical condition, which could reinforce the demand to develop new alternative proposals for medication therapy that replace PIM, with improved quality of life of the elderly population.

\section{Contributions to the area of nursing, health, or public policies}

The study highlights the importance of FHS teams on their potential in monitoring cases and the increase in the sense of $\mathrm{PHC}$ to the elderly population with hypertension, according to their organization and the sense of service offerings and according to the health needs of this population. This research indicates important contributions to the demand for new educational technologies and alternative medication protocols that help health professionals, prescribers, to develop new ways in medication therapy for the elderly population in health care networks, especially in the FHS, reducing the use of PIM and maximizing quality of life and adequate blood pressure control in elderly people with hypertension.

\section{CONCLUSION}

The results of the study showed that anthropometric, clinical, and organizational factors enhance the use of PIM for the elderly. In this sight, the study confirms the need for improvements in clinical practice, aiming at all factors that are inherent to the chronic condition of the elderly and the demand for relevant clinical protocols to help determine the therapeutic plan, with a target to reduce PIM.

Given this scenario, the study warns about the clinical and anthropometric factors of the elderly population, which were allusive to the use of PIM, and it is beneficial for health professionals to perform a more holistic approach to the elderly with hypertension, with a target to attending to physical activity practices and change in diet behavior, to reduce the factors inherent in the use of PIM. Nursing professionals must reduce mechanized consultations, based on the biomedical and hegemonic model, which intensifies the intersectionality and care continuity in health care networks, with essential practices for creating a bond among the elderly, besides carrying out new activities that improve the quality of life of the elderly.

\section{FUNDING}

This study had a financial contribution from the Coordenação de Aperfeiçoamento de Pessoal de Nível Superior (CAPES), Process n. 88882.449287/2019-01.

\section{REFERENCES}

1. Tapela NM, Tshisimogo G, Shatera BP, Letsatsi V, Gaborone M, Madidimalo T, et al. Integrating noncommunicable disease services into primary health care, Botswana. Bull World Health Org. 2019;97:142-53. doi: 10.2471/BLT.18.221424

2. Barreto MS, Mendonça RD, Pimenta AM, Garcia-Vivar C, Marcon SS. Non-use of primary care routine consultations for individuals with hypertension. Cien Saude Colet. 2018;23:795-804. doi: 10.1590/1413-81232018233.12132016

3. Ministério da Saúde (BR). Secretaria de Vigilância em Saúde, Departamento de Vigilância de Doenças e Agravos não Transmissíveis e Promoção da Saúde. Vigitel Brasil 2019: vigilância de fatores de risco e proteção para doenças crônicas por inquérito telefônico: estimativas sobre frequência e distribuição sociodemográfica de fatores de risco e proteção para doenças crônicas nas capitais dos 26 estados brasileiros e no Distrito Federal em 2019. Brasília, DF: Ministério da Saúde;2020.

4. Macinko J, Leventhal DGP, Lima-Costa MF. Primary care and the hypertension care continuum in Brazil. J Ambul Care Manage. 2018;41:3446. doi: 10.1097/JAC.0000000000000222

5. Marques GFM, Rezende DMRP, Silva IP, Souza PC, Barbosa SRM, Penha RM, et al. Polypharmacy and potentially inappropriate medications for elder people in gerontological nursing. Rev Bras Enferm 2018;71:2440-6. doi: 10.1590/0034-7167-2017-0211

6. American Geriatrics Society Beers Criteria ${ }^{\oplus}$ Update Expert Panel. American Geriatrics Society 2019 Updated AGS Beers Criteria ${ }^{\otimes}$ for Potentially Inappropriate Medication Use in Older Adults: 2019 AGS BEERS CRITERIA ${ }^{\oplus}$ UPDATE EXPERT PANEL. J Am Geriatr Soc. 2019;67:674-94. doi: $10.1111 /$ jgs.15767 
7. Almeida TA, Reis EA, Pinto IVL, Ceccato MGB, Silveira MR, Lima MG, et al. Factors associated with the use of potentially inappropriate medications by older adults in primary health care: an analysis comparing AGS Beers, EU (7) PIM List, and Brazilian Consensus PIM criteria. RSAP, 2019;15:370-7. doi: 10.1016/j.sapharm.2018.06.002

8. Bazargan M, Smith JL, King EO. Potentially inappropriate medication use among hypertensive older African-American adults. BMC Geriatr. 2018;18:238. doi: 10.1186/s12877-018-0926-9

9. Vandenbroucke JP, von Elm E, Altman DG, Gøtzsche PC, Mulrow CD, Pocock SJ, et al. Strengthening the Reporting of Observational Studies in Epidemiology (STROBE): explanation and Elaboration. PLoS Med. 2007;4: e297. doi: 10.1371/journal.pmed.0040297

10. Instituto Paranaense de Desenvolvimento Econômico e Social. Caderno Estatístico Município de Maringá [Internet]. Curitiba: IPARDES; 2020 [cited 2020 Sep 19]. Available from: http://www.ipardes.gov.br/cadernos/MontaCadPdf1.php?Municipio=87000\&btOk=ok

11. Ministério da Saúde (BR). Secretaria de Atenção Primária à Saúde. Departamento de Saúde da Família. Carteira de serviços da Atenção Primária à Saúde (CaSAPS): versão profissionais de saúde e gestores. Brasília (DF): 2020 [cited 2020 Sep 19]. Available from: http://bvsms. saude.gov.br/bvs/publicacoes/carteira_servicos_atencao_primaria_saude.pdf

12. Paes NA, Silva CS, Figueiredo TMRM, Cardoso MAA, Lima JO. Satisfação dos usuários hipertensos com os serviços da rede de atenção primária no Brasil: um estudo de validação. Rev Panam Salud Publica. [Internet] 2014;36(2) [cited 2016 Sep 16]. Available from: http://www. scielosp.org/pdf/rpsp/v36n2/03.pdf

13. Rêgo AS, Haddad MCFL, Salci MA, Radovanovic CAT. Acessibilidade ao tratamento da hipertensão arterial na estratégia saúde da família. Rev Gaúcha Enferm. 2018;39. doi: 10.1590/1983-1447.2018.20180037

14. Associação Brasileira de Empresas de Pesquisa. Critério de Classificação Econômica Brasil 2018 [Internet]. Associação Brasileira de Empresas de Pesquisa [cited 2020 Sep 20]. Available from: http://www.abep.org

15. World Health Organization Collaborating Centre for Drug Statistics Methodology. Oslo: World Health Organization Collaborating Centre for Drug Statistics Methodology[Internet]. 2017[cited 2020 Jan 16]. ATC/DDD Index 2017. Available from: http://www.whocc.no/atc_ddd_index/

16. Ministério da Saúde (BR). Ministério da Saúde. Secretaria de Atenção à Saúde, Departamento de Ações Programáticas e Estratégicas. Caderneta de Saúde da Pessoa Idosa: manual de preenchimento [Internet]. Brasília (DF): Ministério da Saúde, 2014[cited 2016 Aug 03]. Available from: http://189.28.128.100/dab/docs/publicacoes/geral/pnab.pdf

17. Associação Brasileira para o Estudo da Obesidade e da Síndrome Metabólica. Diretrizes brasileiras de obesidade 2016[Internet]. 4a ed. São Paulo (SP): ABESO; 2016 [cited 2016 Sep 16]. Available from:http://www.abeso.org.br/uploads/downloads/92/57fccc403e5da.pdf

18. Malachias MVB, Souza WKSB, Plavnik FL, Rodrigues CIS, Brandão AA, Neves MFT, et al. Sociedade Brasileira de Cardiologia. $7^{a}$ Diretriz Brasileira de Hipertensão Arterial. Arq Bras Cardiol [Internet] 2016[cited 2016 Sep 16];107(3). Available from: http://www.scielo.br/pdf/abc/ v107n3s3/0066-782X-abc-107-03-s3-0067.pdf

19. Assumpção D, Ferraz RO, Borim FSA, Neri AL, Francisco PMSB. Pontos de corte da circunferência da cintura e da razão cintura/estatura para excesso de peso: estudo transversal com idosos de sete cidades brasileiras, 2008-2009. Epidemiol Serv Saúde. 2020;29. doi: 10.5123/ S1679-49742020000300003.

20. Pitanga FJG, Lessa I. Sensitivity and specificity of the conicity index as a coronary risk predictor among adults in Salvador, Brazil. Rev Bras Epidemiol. 2004;7:259-69. doi: 10.1590/S1415-790X2004000300004

21. Muhlack DC, Hoppe LK, Stock C, Haefeli WE, Brenner H, Schöttker B. The associations of geriatric syndromes and other patient characteristics with the current and future use of potentially inappropriate medications in a large cohort study. Eur J Clin Pharmacol. 2018;74:1633-44. doi: 10.1007/s00228-018-2534-1

22. Rieckert A, Trampisch US, Klaaßen-Mielke R, Drewelow E, Esmail A, Johansson T, et al. Polypharmacy in older patients with chronic diseases: a cross-sectional analysis of factors associated with excessive polypharmacy. BMC Fam Pract. 2018;19:113. doi: 10.1186/s12875-018-0795-5

23. Araújo CAH, GiehI MWC, Danielewicz AL, Araujo PG, d'Orsi E, Boing AF. Built environment, contextual income, andobesity in older adults: evidence from a population-based study. Cad Saúde Pública. 2018;34. doi: 10.1590/0102-311x00060217

24. Araújo AC, Amaral TLM, Monteiro GTR, de Vasconcellos MTL, Portela MC. Factors associated with low handgrip strength in older people: data of the Study of Chronic Diseases (Edoc-I). BMC Public Health 2020;20:395. doi: 10.1186/s12889-020-08504-z

25. Zhao J, Hu Y, Zhang X, Zhang G, Lin M, Chen X, et al. Efficacy of empowerment strategies for patients with hypertension: a systematic review and meta-analysis. Patient Educ Couns 2020;103:898-907. doi: 10.1016/j.pec.2019.11.025

26. Al-Dahshan A, Al-Kubiasi N, Al-Zaidan M, Saeed W, Kehyayan V, Bougmiza I. Prevalence of polypharmacy and the association with non-communicable diseases in Qatari elderly patients attending primary healthcare centers: a cross-sectional study. PLoS ONE 2020;15:e0234386. doi: 10.1371/journal.pone.0234386

27. Santos MDV, Santos SV, Caccia-BavaMCGG. The prevalence of strategies for cessation of tobacco usein primary health care: an integrative review. Cien Saude Colet. 2019;24:563-72. doi: 10.1590/1413-81232018242.27712016

28. Vincentis A, Gallo P, Finamore P, Pedone C, Costanzo L, Pasina L, et al. Potentially inappropriate medications, drug-drug interactions, and anticholinergic burden in elderly hospitalized patients: does an association exist with post-discharge health outcomes? Drugs Aging. 2020;37:585-93. https://doi.org/10.1007/s40266-020-00767-w

29. Nothelle SK, Sharma R, Oakes A, Jackson M, Segal JB. Factors associated with potentially inappropriate medication use in communitydwelling older adults in the United States: a systematic review. J Pharm Policy Pract. 2019;27:408-23. doi: 10.1111/ijpp.12541 
30. Muhlack DC, Hoppe LK, Saum K-U, Haefeli WE, Brenner H, Schöttker B. Investigation of a possible association of potentially inappropriate medication for older adults and frailty in a prospective cohort study from Germany. Age Ageing 2020;49:20-5. doi: 10.1093/ageing/afz127

31. Rêgo AS, Radovanovic CAT. Adherence of hypertension patients in the Brazil's Family Health Strategy. Rev Bras Enferm. 2018;71(3):1030-7. doi: 10.1590/0034-7167-2017-0297

32. Tavakoly Sany SB, Behzhad F, Ferns G, Peyman N. Communication skills training for physicians improves health literacy and medical outcomes among patients with hypertension: a randomized controlled trial. BMC Health Serv Res. 2020;20:60. doi: 10.1186/ s12913-020-4901-8

33. Queiroz RF, Alvarez AM, Morais LJ, Silva RAR. Perception ofnursing workers on the care of hypertension in older adult. Rev Bras Enferm. 2019;72(Suppl 2):3-13. doi: 10.1590/0034-7167-2016-0681 